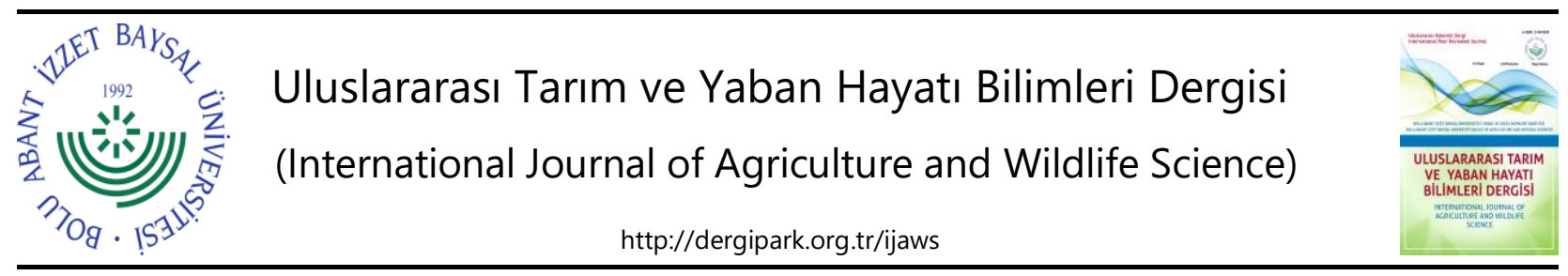

Araştırma Makalesi

\title{
'Eşme' Ayva Çeşidinin Farklı Meyve Kısımlarının Biyoaktif İçerikleri
}

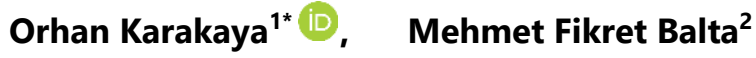 \\ 'Sakarya Uygulamalı Bilimler Üniversitesi, Ziraat Fakültesi, Bahçe Bitkileri Bölümü, Sakarya \\ ${ }^{2}$ Ordu Üniversitesi, Ziraat Fakültesi, Bahçe Bitkileri Bölümü, Ordu
}

Geliş tarihi (Received): 09.07.2021Ｋabul tarihi (Accepted): 02.11.2021

\section{Anahtar kelimeler: Ayva, kabuk, meyve eti, fenolik, antioksidan}

*Sorumlu yazar

orhankarakaya7@gmail.com
Özet. Araştırma, 'Eşme' ayva çeşidinin farklı meyve kısımlarının pH, suda çözünebilir kuru madde, titre edilebilir asitlik, C vitamini, toplam fenolik, toplam flavonoid ve antioksidan aktivitesini (DPPH ve FRAP testlerine göre) belirlemek amacıyla yürütülmüştür. 'Eşme' ayva çeşidinin farklı meyve kısımlarında pH 3.57 (meyve eti)-4.03 (kabuk), suda çözünebilir kuru madde \%5.40 (kabuk)-12.22 (meyve eti), titre edilebilir asitlik \%0.21 (kabuk)-0.78 (meyve eti), C vitamini 11.68 (tüm meyve)-202.27 (kabuk) mg 100 $\mathrm{g}^{-1}$, toplam fenolik 56.78 (meyve eti)-974.32 (kabuk) mg $100 \mathrm{~g}^{-1}$, toplam flavonoid 39.89 (meyve eti)291.10 (kabuk) mg $100 \mathrm{~g}^{-1}$, antioksidan aktivitesi 0.06 (meyve eti)-0.82 (kabuk) mmol $100 \mathrm{~g}^{-1}$ (DPPH testine göre) ve 0.30 (meyve eti)-2.74 (kabuk) mmol $100 \mathrm{~g}^{-1}$ (FRAP testine göre) arasında belirlenmiştir. Farklı meyve kısımlarına göre, toplam fenolik ile antioksidan aktivitesi (DPPH ve FRAP testlerine göre sırasıyla $R^{2}=1.0$ ve $R^{2}=1.0$ ) ve toplam flavonoid ile antioksidan aktivitesi (DPPH ve FRAP testlerine göre sırasıyla $R^{2}=1.0$ ve $R^{2}=1.0$ ) arasında yüksek pozitif bir ilişki tespit edilmiştir. Sonuç olarak, 'Eşme' ayva çeşidinin meyve kabuğunda meyve eti ve tüm meyveye göre toplam fenolik, toplam flavonoid ve antioksidan aktivitesinin daha yüksek olduğu belirlenmiştir.

\section{Bioactive Contents of Different Fruit Parts of 'Eşme' Quince Cultivar}

\section{Keywords:}

Quince, peel, pulp, phenolic, antioxidant

\begin{abstract}
This research was carried out to determine $\mathrm{pH}$, soluble solids content, titratable acidity, vitamin $\mathrm{C}$, total phenolic, total flavonoid and antioxidant activity (according to DPPH and FRAP assays) of different fruit parts of 'Eşme' quince cultivar. $\mathrm{pH}$, soluble solids content, titratable acidity, vitamin $\mathrm{C}$, total phenolic, total flavonoid and antioxidant activity in the different fruit parts of 'Eşme' quince cultivar was determined from 3.57 (pulp) to 4.03 (peel), $5.40 \%$ (peel) to $12.22 \%$ (pulp), $0.21 \%$ (peel) to $0.78 \%$ (pulp), 11.68 (flesh) mg $100 \mathrm{~g}^{-1}$ to 202.27 (peel) mg $100 \mathrm{~g}^{-1}, 56.78$ (pulp) mg $100 \mathrm{~g}^{-1}$ to 974.32 (peel) mg $100 \mathrm{~g}^{-1}, 39.89$ (pulp) mg $100 \mathrm{~g}^{-1}$ to 291.10 (peel) mg $100 \mathrm{~g}^{-1}, 0.06 \mathrm{mmol} 100 \mathrm{~g}^{-1}$ (pulp) to 0.82 (peel) mmol $100 \mathrm{~g}^{-1}$ and 0.30 (pulp) mmol $100 \mathrm{~g}^{-1}$ to 2.74 (peel) mmol $100 \mathrm{~g}^{-1}$, respectively. According to different fruit parts, a high positive relation was determined from total phenolic to antioxidant activity (according to DPPH and FRAP assays $R^{2}=1.0$ and $R^{2}=1.0$, respectively) and total flavonoid to antioxidant activity (according to DPPH and FRAP assays $R^{2}=1.0$ and $R^{2}=1.0$, respectively). Consequently, in the peel of 'Eşme' quince cultivar was determined higher total phenolic, total flavonoid and, antioxidant activity than according to pulp and flesh.
\end{abstract}




\section{Giriş}

Bitkisel gıdalar, yaşam için gerekli temel besin öğelerini karşılamakla birlikte, insan sağlığını teşvik eden ve hastalıkları engelleyici özelliklere sahip fenoliklerin ve antioksidanların önemli bir kaynağıdır. Meyve ve sebzeler kronik hastalıkların riskini azaltan ve insan sağlığını teşvik eden fitokimyasalların önemli bir kısmını içerir (Liu, 2003). Birçok araştırma, kansere sebep olan oksidatif stresin önlenmesinde ve yavaşlatılmasında, fenolikler, antioksidanlar ve karotenoidler gibi çeşitli fitokimyasalların etkili olduğunu ortaya koymuştur (Alesiani ve ark., 2010). Bunun yanında, son araştırmalar meyve ve sebzelerin zengin bir diyet ile ilişkili sağlığa yararlarını ortaya çıkarmıştır (Ricceri ve ark., 2017; Jhee ve ark., 2019).

Vitaminlerce zengin, önemli bir lif kaynağı ve düşük yağ içeriğine sahip olan meyve ve sebzelerin düzenli olarak tüketilmesi tavsiye edilmektedir. Düşük yağ içeriğine sahip olan ayva, birçok meyve türünden daha önemli besin içeriklerine sahiptir (Szychowski ve ark., 2014; Rasheed ve ark., 2018). Ayva organik asitler (malik asit, askorbik asit, aspartik asit, sitrik asit ve glutamik asit), mineral elementler (kalisyum, fosfor, magnezyum, potasyum ve demir), karbonhidratlar, lifler (çoğunlukla pektik ve selülozik polisakkaritler), proteinler, amino asitler, vitaminler ve tanenler bakımından zengindir (Thomas ve ark., 2000; Hegedus ve ark., 2013; Ali ve ark., 2015). Bunun yanında, ayva insan sağlığını teşvik eden ve birçok hastalığa karşı koruyucu etkiye sahip olan antioksidanlar ve fenoliklerin önemli bir kaynağıdır (Silva ve ark., 2002; Rop ve ark., 2011). Ayva içeriğindeki antioksidanlar ve fenoliklerden dolayı anti-kansorejen (Carvalho ve ark., 2010), anti-proliferatif (Alesiani ve ark., 2010), anti-ülseratif (Hamauzu ve ark., 2006), anti-mikrobiyal (Shaida ve ark., 2020) ve anti-inflamatuar (iltihap sökücü) (Essafi-Benkhadir ve ark., 2012; Shaida ve ark., 2020) özelliklere sahiptir.

Ayva meyvesi sert, buruk ve asitli olması nedeniyle genellikle reçel, marmelat, püre, jöle ve meyve suyu yapımında kullanılır (Antoniewska ve ark., 2017). Bu değerlendirme şekillerinin başlıca yan ürünü kabuktur. Birçok araştırıı toplam fenolik ve antioksidan içeriğinin meyve kabuğunda tüm meyve ve meyve etine göre daha fazla olduğunu bildirmektedir (Ajila ve ark., 2007; Vieira ve ark., 2009). Benzer şekilde, fenolik bileşiklerin önemli bir kaynağı olan ayvada, bu bileşiklerin büyük bir kısmı kabukta bulunur (Silva ve ark., 2002). Stojanovic ve ark. (2017), Sırbistan'da yetiştirilen ayva genotiplerinin meyve eti ve kabuğunda sırasıyla toplam fenolik içeriğini 71.03-158.89

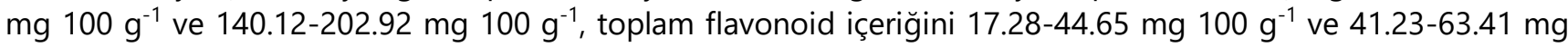
$100 \mathrm{~g}^{-1}$ arasında bildirmişlerdir.

Ayva meyvesinin etinde ve kabuğunda bulunan fenolik bileşikler farklılık gösterir. Meyve etinde çoğunlukla kafeoilkinik asitler, meyve kabuğunda ise hem kafeoilkinik asitler hem de önemli miktarda flavonol glikozitler bulunur (Papp ve ark., 2013). Meyve kabuğunun neo-klorojenik asit (5-O-caffeoylquinic acid), klorojenik asit (3$O$-caffeoylquinic acid) ve rutin (quercetin-3-rutinoside), meyve etinin ise neo-klorojenik asit, klorojenik asit ve izoklorojenik asit (3,5-dicaffeoylquinic acid) bakımından zengin olduğu belirlenmiştir. Bunun yanında izoklorojenik asit, hiperozid (quercetin-3-galactoside) ve izokuersetin (quercetin-glucoside)'in kabukta bulunan diğer önemli bileşikler olduğu bildirilmiştir (Stojanovic ve ark., 2017). Bu fenolik bileşiklerin her birinin sağlık üzerine farklı etkilerinin olduğu ifade edilmektedir (Francini ve Sebastiani, 2013).

Ayva yetiştiriciliği açısından oldukça uygun ekolojik koşullara sahip olan ülkemizde, Eşme, Limon, Ekmek, Demir ve Bardak yetiştiriciliği yapılan önemli çeşitlerdir. Marmara Bölgesi başta olmak üzere, Eğe, Karadeniz ve Akdeniz Bölgeleri ayva yetiştiriciliği açısından önemli bir potansiyele sahiptir. Ülkemiz yaklaşık 181 bin ton ayva üretimiyle dünyada lider konumdadır. Ayva üretim miktarı bakımından ülkemizi Çin, Özbekistan ve İran takip etmektedir (FAO, 2021). Önemli bir ayva üreticisi olan ülkemizde ayvanın biyokimyasal özelliklerini belirlemeye yönelik yürütülen araştırma sayısı oldukça azdır. Bunun yanında ayva çeşitlerimizin farklı meyve kısımlarının biyokimyasal özelliklerinin incelendiği bir araştırma da bulunmamaktadır. Bu bakımdan ülkemizde yetiştirilen ayva çeşit ve genotiplerinin biyokimyasal özelliklerini belirlemeye yönelik yapılacak çalışmalar önemlidir.

Bu araştırma, ülkemizin önemli ayva çeşitlerinden 'Eşme' çeşidinin farklı meyve kısımlarının (meyve eti, meyve kabuğu ve tüm meyvede) $\mathrm{pH}$, suda çözünebilir kuru madde, titre edilebilir asitlik, C vitamini, toplam fenolik, toplam flavonoid ve antioskidan aktivitesini belirlemek amacıyla yürütülmüştür.

\section{MATERYAL VE METOT}

Araştırma, 2019 ve 2020 yıllarında Ordu Üniversitesi Ziraat Fakültesi Uygulama ve Araştırma Arazisinde yürütülmüştür. Araştırmanın materyalini çöğür anaç üzerine aşılı Eşme ayva çeşidi ile tesis edilmiş 5 yaşlı bahçeden alınan meyveler oluşturmuştur. Araştırmanın yürütüldüğü bahçe $3.5 \times 4.0 \mathrm{~m}$ sıra arası ve üzeri mesafelerle tesis edilmiş ve ağaçlara goble terbiye sistemi uygulanmıştır. Araştırma süresince kültürel ve teknik uygulamalar düzenli olarak yerine getirilmiştir. Sulama damla sulama yöntemi kullanılarak yapılmıştır. 
Araştırma 3 tekerrürlü ve her tekerrürde 3 ağaç olacak şekilde planlanmıştır. Analizler için, hasat zamanında her ağaçtan 10 meyve derilmiştir. Hasat edilen meyvelerde $\mathrm{pH}$, suda çözünebilir kuru madde (SÇKM), titre edilebilir asitlik (TA), C vitamini, toplam fenolik, toplam flavonoid ve antioksidan aktivitesi (DPPH ve FRAP testlerine göre) incelenmiştir. Biyokimyasal içerikler meyve kabuğunda, meyve etinde ve tüm meyvede (kabuk ve meyve eti birlikte) belirlenmiştir.

\section{pH, Suda Çözünebilir Kuru Madde (\%) ve Titre Edilebilir Asitlik (\%)}

Incelenen eşme ayva çeşidinin farklı meyve kısımlarından elde edilen meyve suyunda $\mathrm{pH}$ değeri dijital $\mathrm{pH}$ metre (Hanna, HI4221, ABD) ve suda çözünebilir kuru madde içeriği dijital refraktrometre (Atago, PAL-1, ABD) kullanılarak belirlenmiştir. Titre edilebilir asitlik içeriğinin belirlenmesi için elde edilen meyve suyu saf su ile seyreltilerek (1:1), sodyum hidroksit $(0.1 \mathrm{~N})$ ile $\mathrm{pH}$ değeri 8.1'e gelinceye kadar titre edilmiştir.

\section{Vitamini ( $\left.m g 100 \mathrm{~g}^{-1}\right)$}

C vitamini içeriği meyve suyunda reflektometre (RQ flex, Plus 10, Merck, Almanya) yardımıyla belirlenmiştir. Okunan değer mg $100 \mathrm{~g}^{-1}$ olarak ifade edilmiştir.

\section{Toplam Fenolik ( $m g 100 \mathrm{~g}^{-1}$ )}

Hazırlanan stok çözeltiden $1000 \mu \mathrm{L}$ alınarak üzerine $3.6 \mathrm{~mL}$ saf su, $100 \mu \mathrm{L}$ folin reaktifi ve $300 \mu \mathrm{L} \mathrm{Na} \mathrm{CO}_{3}$ ilave edilmiş ve 2 saat süreyle inkübasyona bırakılmıştır. Hazırlanan numunelerde absorbans değerleri spektrofotometre (Shimadzu, UVmini-1240, Japonya) 760 nm'de belirlenmiştir. Okunan absorbans değerleri gallik aside eş değer mg $100 \mathrm{~g}^{-1}$ olarak ifade edilmiştir (Beyhan ve ark., 2010).

\section{Toplam Flavonoid (mg $100 \mathrm{~g}^{-1}$ )}

Hazırlanan stok çözeltiden $1000 \mu \mathrm{L}$ alınarak üzerine $3.3 \mathrm{~mL}$ methanol, $100 \mu \mathrm{L}$ sodyum asetat ve $100 \mu \mathrm{L}$ aleminyum klorür ilave edilmiş ve 40 dakika inkübasyona bırakılmıştır. Hazırlanan numunelerde absorbans değerleri spektrofotometre $415 \mathrm{~nm}$ 'de ölçülmüştür. Okunan absorbans değerleri kuersetin cinsinden hesaplanarak, mg $100 \mathrm{~g}^{-1}$ olarak ifade edilmiştir (Zhishen ve ark., 1999).

\section{Antioksidan Aktivitesi (mmol $100 \mathrm{~g}^{-1}$ ) \\ DPPH Yöntemi}

DPPH yöntemine göre antioksidan aktivitesi Blois (1958)'e göre belirlenmiştir. Hazırlanan stok çözeltiden 200 $\mu \mathrm{L}$ alınarak üzerine $2.8 \mathrm{~mL}$ etil alkol ve $1 \mathrm{~mL}$ DPPH çözeltisi ilave edilmiştir. Absorbans değerleri spektrofotometrede $517 \mathrm{~nm}$ 'de ölçülmüştür. Okunan değerler torolox cinsinden mmol $100 \mathrm{~g}^{-1}$ olarak ifade edilmiştir.

\section{FRAP Yöntemi}

FRAP yöntemine göre antioksidan aktivitesi Benzie ve Strain (1996)'e göre belirlenmiştir. Hazırlanan stok çözeltiden $200 \mu \mathrm{L}$ alınarak üzerine $1050 \mu \mathrm{L}$ fosfat tamponu ve $1.25 \mathrm{~mL}$ potasyum ferrik siyanit ilave edilerek, 30 dakika $50^{\circ} \mathrm{C}$ 'de inkübasyona bırakılmıştır. Daha sonra numuneler üzerine $1.25 \mathrm{~mL}$ TCA ve $250 \mu \mathrm{L}$ demir klorür ilave edilmiştir. Absorbans değerleri spektrofotometrede 700 nm'de ölçülmüştür. Okunan değerler torolox cinsinden hesaplanarak, mmol $100 \mathrm{~g}^{-1}$ olarak ifade edilmiştir.

\section{istatistiksel Analizler}

Verilerin değerlendirilmesi SPSS 23.0 istatistik paket programı kullanılarak yapılmıştır. Ortalamalar arasındaki farklılık Tukey çoklu karşılaştırma yöntemi kullanılarak \%5 önem seviyesinde belirlenmiştir.

\section{BULGULAR VE TARTIŞMA}

Incelenen Eşme ayva çeşidinde pH değeri tüm meyvede 3.68, meyve etinde 3.57 ve meyve kabuğunda 4.03; suda çözünebilir kuru madde tüm meyvede \%11.13, meyve etinde \%12.22 ve meyve kabuğunda \%5.40; titre edilebilir asitlik tüm meyvede \%0.76, meyve etinde \%0.78 ve meyve kabuğunda \%0.21 olarak belirlenmiştir (Çizelge 1). Ayvada farklı meyve kısımlarının pH, suda çözünebilir kuru madde ve titre edilebilir asitlik içeriğinin belirlenmesine yönelik bir araşıımaya rastlanılmamıştır. Ancak, farklı armut genotipleri ile yapılan bir araştırmada meyve kabuğunda $\mathrm{pH}$ değerinin yüksek, suda çözünebilir kuru madde ve titre edilebilir asitlik içeriklerinin ise düşük olduğu bildirilmiştir (Öztürk ve ark., 2015). Mevcut çalışmada da benzer durum tespit edilmiştir. Bunun 
yanında, Eşme ayva çeşidinde yapılan araştırmalarda, Ankara yöresinde suda çözünebilir kuru madde \%13.4 ve titre edilebilir asitlik 0.95 (Tuna-Güneş ve Dumanoğlu, 2005); Tokat yöresinde pH 2.98, suda çözünebilir kuru madde \%13.63 ve titre edilebilir asitlik 0.99 (Gerçekcioğlu ve ark., 2014); Şanlıurfa yöresinde pH 3.49, suda çözünebilir kuru madde \%15.60 ve titre edilebilir asitlik 0.63 (Bolat ve İkinci, 2015); Eğirdir (Isparta) ekolojik koşullarında suda çözünebilir kuru madde \%13.40 ve titre edilebilir asitlik 0.88 (Çalhan ve Koyuncu, 2018) olarak bildirilmiştir. Mevcut çalışmada meyve etine ait $\mathrm{pH}$ ve titre edilebilir asitlik değerlerinin araştırıcıların bulgularıyla uyumlu, suda çözünebilir kuru madde değerinin ise düşük olduğu belirlenmiştir. Görülen bazı farklılıkların ise başta ekolojik koşullar olmak üzere, meyvenin olgunluk durumundan, teknik ve kültürel uygulamalardan kaynaklı olabileceği düşünülmektedir.

Çizelge 1. Eşme ayva çeşidinin farklı meyve kısımlarının pH, suda çözünebilir kuru madde, titre edilebilir asitlik ve $\mathrm{C}$ vitamini içeriği.

Table 1. pH, soluble solids content, titratable acidity and vitamin C content of different fruit parts of 'Eşme' quince cultivar.

\begin{tabular}{lcccc}
\hline Meyve kısımları & $\mathbf{p H}$ & $\begin{array}{c}\text { Suda çözünebilir kuru madde } \\
(\%)\end{array}$ & $\begin{array}{c}\text { Titre edilebilir asitlik } \\
(\mathbf{\%})\end{array}$ & $\begin{array}{c}\text { C vitamini } \\
\left(\mathbf{m g ~}_{\mathbf{1 0 0} \mathbf{g}^{-1} \mathbf{)}}\right.\end{array}$ \\
\hline Tüm meyve & $3.68 \pm 0.01 \mathrm{~b}^{*}$ & $11.13 \pm 0.10 \mathrm{~b}$ & $0.76 \pm 0.01 \mathrm{~b}$ & $13.60 \pm 0.15 \mathrm{~b}$ \\
Meyve eti & $3.57 \pm 0.01 \mathrm{C}$ & $12.22 \pm 0.12 \mathrm{a}$ & $0.78 \pm 0.01 \mathrm{a}$ & $11.70 \pm 0.29 \mathrm{C}$ \\
Kabuk & $4.03 \pm 0.03 \mathrm{a}$ & $5.40 \pm 0.05 \mathrm{C}$ & $0.21 \pm 0.01 \mathrm{c}$ & $20.50 \pm 0.25 \mathrm{a}$ \\
\hline
\end{tabular}

${ }^{*}$ Aynı sütunda aynı harf ile gösterilen ortalamalar arasındaki fark önemsizdir $(p<0.05)$.

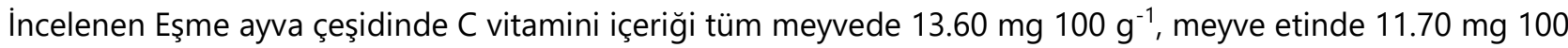
$\mathrm{g}^{-1}$ ve meyve kabuğunda $20.50 \mathrm{mg} 100 \mathrm{~g}^{-1}$ olarak tespit edilmiştir (Çizelge 1). Ayvada farklı meyve kısımlarının C vitamini içeriğinin belirlendiği bir araştırmaya rastlanılmamıştır. Ancak farklı meyve türleri ile yapılan araştırmalarda C vitamini içeriğinin meyve kabuğunda meyve etine göre daha yüksek olduğu bildirilmiştir (Öztürk ve ark., 2015; Liu ve ark., 2015). Mevcut çalışmada da C vitamini içeriği bakımından benzer durum belirlenmiştir. Bunun yanında $C$ vitamini içeriği, Çek Cumhuriyeti'nde yetiştirilen bazı ayva çeşitleri ve genotiplerinde tüm meyvede $41.12-79.31 \mathrm{mg} 100 \mathrm{~g}^{-1}$ (Rop ve ark., 2011), Polonya'da yetiştirilen bazı ayva çeşitlerinde tüm meyvede 5.9-26.4 $100 \mathrm{~g}^{-1}$ (Wojdylo ve ark., 2013), Pakistan'da yetiştirilen farklı ayva genotiplerinde tüm meyvede 15.14-

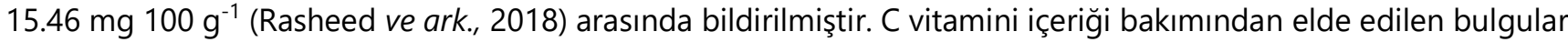
büyük oranda araştıııııların bulgularıyla benzerlik göstermektedir. Görülen bazı farklılıkların başta çeşit ve ekolojik koşullar olmak üzere, olgunluk durumu, kültürel ve teknik uygulamalardan kaynaklanabileceği düşünülmektedir.

Fenolik bileşikler doğada yaygın olan sekonder metabolitlerdir. Fenolikler, antioksidan aktiviteleri nedeniyle insan sağlığını teşvik eden önemli bileşiklerdir (Silva ve ark., 2008). İncelenen Eşme ayva çeşidinde toplam fenolik içeriği tüm meyvede $100.9 \mathrm{mg} 100 \mathrm{~g}^{-1}$, meyve etinde $56.8 \mathrm{mg} 100 \mathrm{~g}^{-1}$ ve meyve kabuğunda $974.3 \mathrm{mg} 100 \mathrm{~g} \mathrm{~g}^{-1}$ olarak belirlenmiştir (Çizelge 2). Toplam fenolik içeriği, Ankara yöresinde yetiştirilen Eşme ayva çeşidinde tüm

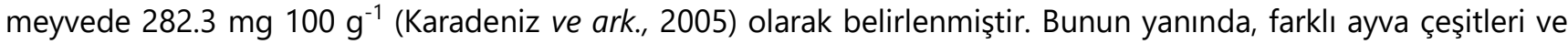

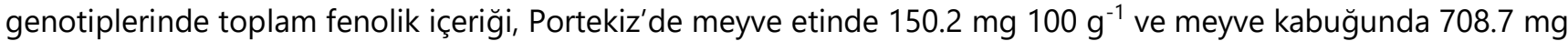

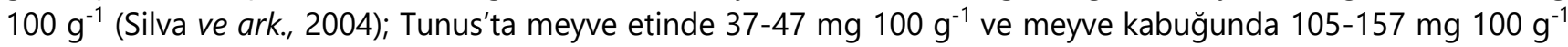
(Fattouch ve ark., 2007); İspanya'da yetiştirilen 9 ayva genotipinde meyve etinde $40-100 \mathrm{mg} 100 \mathrm{~g}^{-1}$ ve meyve kabuğunda 200-430 mg $100 \mathrm{~g}^{-1}$ (Legua ve ark., 2013); Sırbistan'da yetiştirilen ayva genotiplerinde meyve etinde 71.03-158.89 mg $100 \mathrm{~g} \mathrm{~g}^{-1}$ ve meyve kabuğunda 140.12-202.92 mg $100 \mathrm{~g}^{-1}$ arasında bildirilmiştir (Stajonovic ve ark., 2017). Farklı ayva çeşitleri ve genotipleri ile yürütülen araştırmalar incelendiğinde meyve kabuğunun meyve etine göre daha yüksek toplam fenolik içeriğine sahip olduğu görülmektedir. Mevcut çalışmada da toplam fenolik içeriğinin meyve kabuğunda daha yüksek olduğu belirlenmiştir. Ayvada toplam fenolik içeriğinin genetik yapı (Legua ve ark., 2013; Wojdylo ve ark., 2013), ekolojik koşullar (Silva ve ark., 2005), meyvenin olgunluk durumu (Blanda ve ark., 2020), teknik ve kültürel uygulamalardan (Grinan ve ark., 2019) etkilenebileceği rapor edilmiştir.

Antioksidan aktiviteye sahip olan flavonoidler, fenolik bileşiklerin en geniş grubudur (Middleton ve

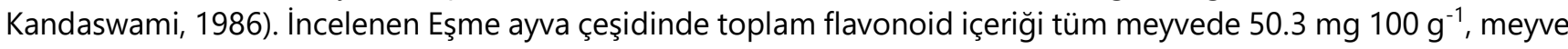

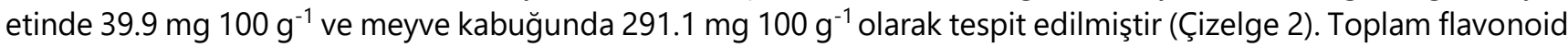
içeriği Ankara yöresinde yetiştirilen Eşme ayva çeşidinde tüm meyvede 119.8 mg $100 \mathrm{~g} \mathrm{~g}^{-1}$ (Karadeniz ve ark., 2005) olarak bildirilmiştir. Bunun yanında, farklı ayva çeşitleri ve genotiplerinde toplam flavonoid içeriği, Sırbistan'da

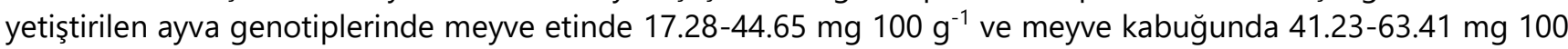
$\mathrm{g}^{-1}$ (Stajonovic ve ark., 2017) arasında belirlenmiştir. Hem mevcut çalışma hem de farklı ayva genotipleri ile yürütülen araştırmanın sonuçları fenolik bileşiklerin önemli bir kısmını oluşturan flavonoidlerin meyve kabuğunda meyve etine göre daha fazla olduğunu göstermiştir. 
Çizelge 2. Eşme ayva çeşidinin farklı meyve kısımlarının toplam fenolik, toplam flavonoid ve antioksidan aktivitesi (DPPH ve FRAP testlerine göre).

Table 2. Total phenolics, total flavonoids and antioxidants activity (according to DPPH and FRAP assays) of different fruit parts of 'Eşme' quince cultivar.

\begin{tabular}{|c|c|c|c|c|}
\hline Meyve kısımları & 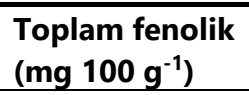 & 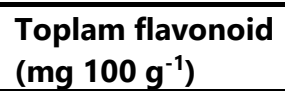 & $\begin{array}{l}\text { DPPH } \\
\left(\mathrm{mmol} 100 \mathrm{~g}^{-1}\right)\end{array}$ & $\begin{array}{l}\text { FRAP } \\
\left(\mathrm{mmol} 100 \mathrm{~g}^{-1}\right)\end{array}$ \\
\hline Tüm meyve & $100.9 \pm 1.26 b^{*}$ & $50.3 \pm 1.91 b$ & $0.09 \pm 0.00 \mathrm{~b}$ & $0.42 \pm 0.01 \mathrm{~b}$ \\
\hline Meyve eti & $56.8 \pm 0.33 c$ & $39.9 \pm 4.28 b$ & $0.06 \pm 0.00 c$ & $0.30 \pm 0.03 c$ \\
\hline Kabuk & $974.3 \pm 24.18 a$ & $291.1 \pm 8.07 \mathrm{a}$ & $0.82 \pm 0.01 a$ & $2.74 \pm 0.06 a$ \\
\hline
\end{tabular}

*Aynı sütunda aynı harf ile gösterilen ortalamalar arasındaki fark önemsizdir $(p<0.05)$.

Antioksidanlar insan sağlığını teşvik eden önemli maddelerdir. Birçok hastalığa karşı koruyucu ve engelleyici etkiye sahip olan antioksidanların en önemli kaynağı meyvelerdir (Valko ve ark., 2007; Wootton-Beard ve Ryan, 2011). Farklı meyve türlerinde yapılan araştırmalarda meyve kabuğunun meyve etine göre antioksidan aktivitesinin daha yüksek olduğu bildirilmiştir (Manzoor ve ark., 2012; Kolniak-Ostek, 2016). İncelenen Eşme ayva çeşidinde antioksidan aktivitesi DPPH ve FRAP testlerine göre sırasıyla tüm meyvede $0.09 \mathrm{mmol} 100 \mathrm{~g}^{-1}$ ve $0.42 \mathrm{mmol} 100$ $\mathrm{g}^{-1}$; meyve etinde $0.06 \mathrm{mmol} 100 \mathrm{~g}^{-1}$ ve $0.30 \mathrm{mmol} 100 \mathrm{~g}^{-1}$; meyve kabuğunda $0.82 \mathrm{mmol} 100 \mathrm{~g}^{-1}$ ve $2.74 \mathrm{mmol}$ $100 \mathrm{~g}^{-1}$ olarak tespit edilmiştir (Çizelge 2). Antioksidan aktivitesi, Ankara yöresinde yetiştirilen Eşme ayva çeşidinde tüm meyvede DPPH testine göre \%57.5 (Karadeniz ve ark., 2005) ve Macaristan'da yetiştirilen farklı ayva çeşitlerinde FRAP testine göre tüm meyvede 5.99-63.10 mmol $100 \mathrm{~g}^{-1}$ arasında belirlenmiştir (Papp ve ark., 2013). Bunun yanında, İspanya'da yetiştirilen 9 ayva genotipinde antioksidan aktivitesinin meyve kabuğunda meyve etine göre 7-8 kat daha fazla olduğu bildirilmiştir (Legua ve ark., 2013). Mevcut çalışmada da antioksidan aktivitesi meyve kabuğunda meyve etine göre 9 (FRAP testine göre) ile 14 kat (DPPH testine göre) daha fazla belirlenmiştir. Ayvada antioksidan aktivitesinin genetik yapı (Legua ve ark., 2013; Wojdylo ve ark., 2013), ekolojik koşullar (Silva ve ark., 2005), bakım şartları (Grinan ve ark., 2019) ve meyvenin olgunluk durumundan (Blanda ve ark., 2020) etkilenebileceği ifade edilmiştir.

Eşme ayva çeşidinde farklı meyve kısımlarına göre, toplam fenolik ile antioksidan aktivitesi (DPPH ve FRAP testlerine göre sirasıyla $r=1.0^{\star *}$ ve $\left.r=1.0^{* \star *}\right)$ ve toplam flavonoid $\left(r=1.0^{\star *}\right)$ arasında, toplam flavonoid ile antioksidan aktivitesi (DPPH ve FRAP testlerine göre sırasıyla $r=1.0^{* *}$ ve $r=1.0^{* *}$ ) arasında pozitif bir kolerasyon belirlenirken, titre edilebilir asitlik ile antioksidan aktivitesi (DPPH ve FRAP testlerine göre sırasıyla $r=-1.0^{*}$ ve $r=-$ $1.0^{\star *}$ ) ve toplam flavonoid $\left(r=-1.0^{* *}\right)$ arasında negatif bir kolerasyon belirlenmiştir $(p<0.05)$ (Çizelge 3$)$. Bunun yanında, toplam fenolik ile antioksidan aktivitesi (DPPH ve FRAP testlerine göre sırasıyla $R^{2}=1.0$ ve $R^{2}=1.0$ ) ve toplam flavonoid ile antioksidan aktivitesi (DPPH ve FRAP testlerine göre sırasıyla $R^{2}=1.0$ ve $R^{2}=1.0$ ) arasında güçlü pozitif bir ilişki tespit edilmiştir (Şekil 1).

Çizelge 3. Incelenen biyokimyasal özellikler arasında önemli bulunan ilişkiler.

Table 3. Important relations in the between investigated biochemical properties.

\begin{tabular}{llll}
\hline & Toplam flavonoid & Toplam fenolik & Titre edilebilir asitlik \\
\hline DPPH & $1.0^{* *}$ & $1.0^{*}$ & $-1.0^{*}$ \\
FRAP & $1.0^{\star *}$ & $1.0^{\star * *}$ & $-1.0^{* *}$ \\
Toplam flavonoid & - & $1.0^{* *}$ & $-1.0^{* *}$ \\
\hline
\end{tabular}

${ }^{*} p<0.05 ;{ }^{* *} p<0.005 ;{ }^{* \star *} p<0.0001$ 

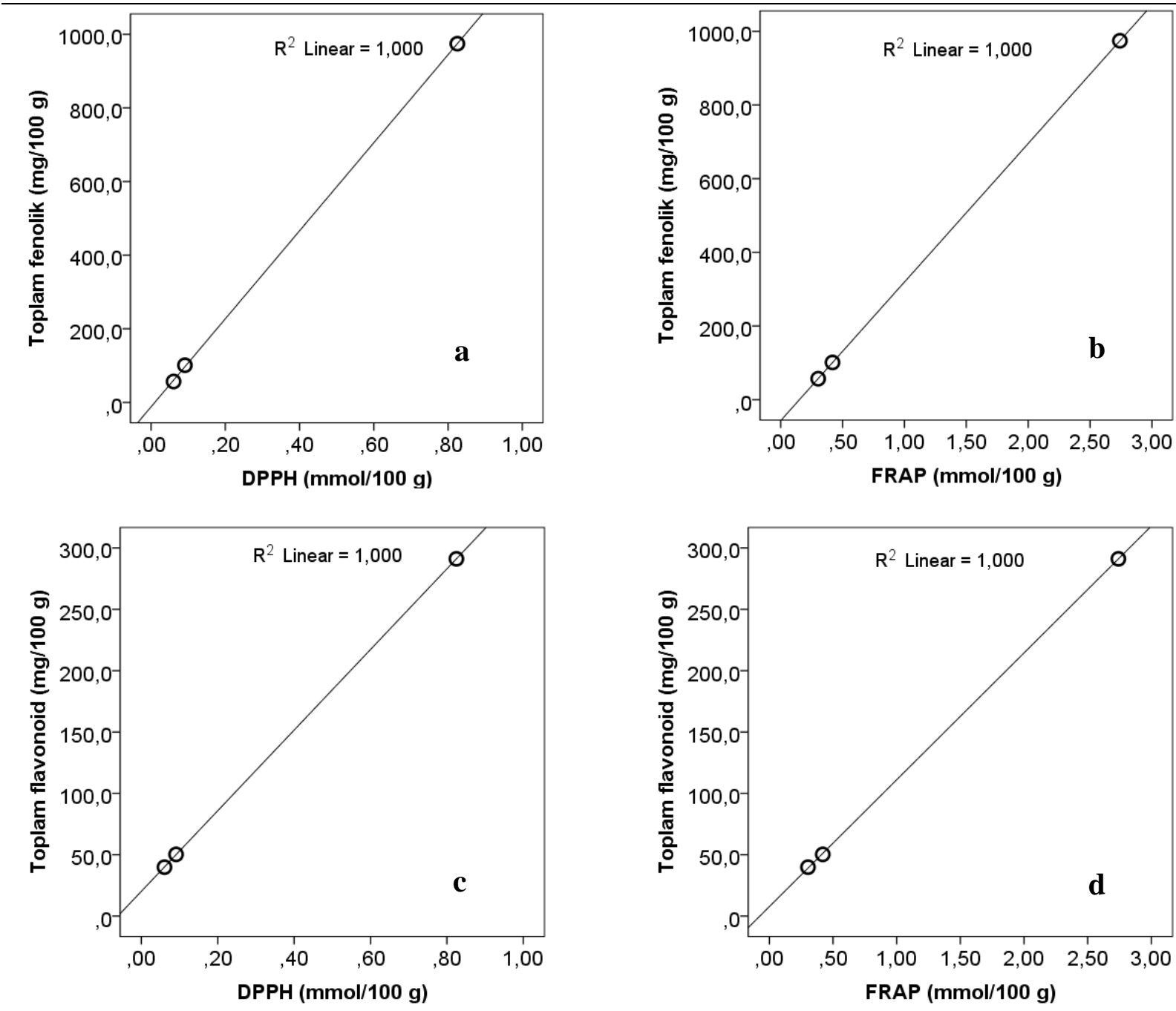

Şekil 1. Toplam fenolik ile DPPH (a) ve FRAP (b); toplam flavonoid ile DPPH (c) ve FRAP (d) arasındaki ilişkiler. Figure 1. Relations from DPPH (a) and FRAP (b) with total phenolics; DPPH (c) and FRAP (d) with total flavonoids.

\section{SONUÇ}

'Eşme' ayva çeşidinin farkı meyve kısımlarının C vitamini, toplam fenolik, toplam flavonoid ve antioksidan aktivitesinin belirlendiği çalışmada, bu özellikler bakımından meyvenin kısımları arasında önemli farklılıkların olduğu tespit edilmiştir. Nitekim, meyve kabuğunda meyve eti ve tüm meyveye göre daha fazla toplam fenolik (9-17 kat), toplam flavonoid (6-7 kat) ve antioksidan aktivite (6-14 kat) belirlenmiştir. Benzer şekilde, $C$ vitamini içeriği de kabukta meyve etine göre yaklaşık 2 kat daha fazla bulunmuştur.

Sonuçlar, ayva kabuğunun meyve etine göre insan sağlığını teşvik eden fenoliklerin ve antioksidanların önemli bir kaynağı olduğunu göstermiştir. Bu durum, bu tür meyvelerde kabuğun soyularak tüketilmesi sonucunda önemli besin kayıplarının olabileceğini göstermiştir. Bu nedenle, biyoaktif bileşiklerin önemli bir kaynağı olan ayvanın kabukla birlikte tüketilmesi, bu maddelerden en üst düzeyde fayda sağlamak açısından önemlidir. Bunun yanında, ayvanın sanayide farklı ürünlere işlenmesi neticesinde yan ürün olarak ortaya çıkan meyve kabuğu gıdaların fenolik ve antioksidan içeriklerini arttırmak için kullanılabilir. Bu anlamda ve ülkemizde yetiştirilen diğer ayva çeşit ve genotiplerinin biyokimyasal özelliklerini belirlemeye yönelik yapılacak çalışmalar önem arz etmektedir.

\section{ÇIKAR ÇATIŞMASI}

Yazarlar arasında herhangi bir çıkar çatışması bulunmamaktadır. 


\section{YAZAR KATKISI}

Yazarlar makaleye eşit oranda katkı sağlamıştır.

\section{KAYNAKLAR}

Ajila, C. M., Naidu, K. A., Bhat, S. G., \& Rao, U. P. (2007). Bioactive compounds and antioxidant potential of mango peel extract. Food Chemistry, 105(3), 982-988.

Alesiani, D., Canini, A., D'Abrosca, B., DellaGreca, M., Fiorentino, A., Mastellone, C., Monaco, P., \& Pacifico, S. (2010). Antioxidant and antiproliferative activities of phytochemicals from quince (Cydonia vulgaris) peels. Food Chemistry, 118(2), $199-207$.

Ali, N., Abbas, A., Ali, A., Shahnawaz, M., Hussain, A., \& Hussain, A. (2015). Physio-Chemical Nutritional and Sensory Evaluation of Local Quince Fruit of Nomal Village, Gilgit-Baltistan, Pakistan. Sciences, 4(6), 600-608.

Benzie, I. F., \& Strain, J. J. (1996). The ferric reducing ability of plasma (FRAP) as a measure of "antioxidant power": the FRAP assay. Analytical Biochemistry, 239(1), 70-76.

Beyhan, Ö., Elmastaş, M., \& Gedikli, F. (2010). Total phenolic compounds and antioxidant capacity of leaf, dry fruit and fresh fruit of feijoa (Acca sellowiana, Myrtaceae). Journal of Medicinal Plant Research, 4, 1065-1072.

Blanda, G., Rodrıguez-Roque, M. J., Comandini, P., Flores-Cordova, M. A., Salas-Salazar, N. A., Oscar, C. A., \& Soto-Caballero, M. C. (2020). Phenolic profile and physicochemical characterization of quince (Cydonia oblonga Mill) fruits at different maturity index. Notulae Botanicae Horti Agrobotanici Cluj-Napoca, 48(4), 2306-2315.

Blois, M. S. (1958). Antioxidant determinations by the use of a stable free radical. Nature, 181(4617), 1199-1200.

Bolat, İ., \& İkinci, A. (2015). Eşme ayva (Cydonia oblonga Miller) çeşidinin GAP Bölgesindeki performansı. Harran Tarım ve Gıda Bilimleri Dergisi, 19(1), 16-23.

Carvalho, M., Silva, B. M., Silva, R., Valentao, P., Andrade, P. B., \& Bastos, M. L. (2010). First report on Cydonia oblonga Miller anticancer potential: differential antiproliferative effect against human kidney and colon cancer cells. Journal of Agricultural and Food Chemistry, 58(6), 3366-3370.

Çalhan, Ö., \& Koyuncu, M. A. (2018). Eşme Ayva (Cydonia oblonga Mill.) Çeşidinde Optimum Derim Tarihini Belirlemek İçin Uygun Kriterlerin Seçimi. Yüzüncü Yıl Üniversitesi Tarım Bilimleri Dergisi, 28(2), 215-225.

Essafi-Benkhadir, K., Refai, A., Riahi, I., Fattouch, S., Karoui, H., \& Essafi, M. (2012). Quince (Cydonia oblonga Miller) peel polyphenols modulate LPS-induced inflammation in human THP-1-derived macrophages through NF-KB, p38MAPK and Akt inhibition. Biochemical and Biophysical Research Communications, 418(1), 180-185.

FAO. (2021). Food and agriculture organization. https://www.fao.org/faostat/en/\#data/QCL. Erişim tarihi: 26 Ekim 2021.

Fattouch, S., Caboni, P., Coroneo, V., Tuberoso, C. I., Angioni, A., Dessi, S., Marzouki, N., \& Cabras, P. (2007). Antimicrobial activity of Tunisian quince (Cydonia oblonga Miller) pulp and peel polyphenolic extracts. Journal of Agricultural and Food Chemistry, 55(3), 963-969.

Francini, A., \& Sebastiani, L. (2013). Phenolic compounds in apple (Malus x domestica Borkh.): compounds characterization and stability during postharvest and after processing. Antioxidants, 2(3), 181-193.

Gerçekcioğlu, R., Gencer, S., \& Atasever, Ö. Ö. (2014). Tokat ekolojisinde yetiştirilen "Eşme" ve "Limon" ayva (Cydonia vulgaris L.) çeşitlerinin bitkisel ve pomolojik özellikleri. International Journal of Agricultural and Natural Sciences, 7(1), 01-05.

Grinan, I., Galindo, A., Rodriguez, P., Morales, D., Corell, M., Centeno, A., Collado-Gonzalez, J., Torrecilas, A., CarbonellBarrachina, A.A., \& Hernández, F. (2019). Volatile composition and sensory and quality attributes of quince (Cydonia oblonga Mill.) fruits as affected by water stress. Scientia Horticulturae, 244, 68-74.

Hamauzu, Y., Inno, T., Kume, C., Irie, M., \& Hiramatsu, K. (2006). Antioxidant and antiulcerative properties of phenolics from Chinese quince, quince, and apple fruits. Journal of Agricultural and Food Chemistry, 54(3), 765-772.

Hegedus, A., Papp, N., \& Stefanovits-Bányai, É. (2013). review of nutritional value and putative health-effects of quince (Cydonia oblonga Mill.) fruit. International Journal of Horticultural Science, 19(3-4), 29-32.

Jhee, J. H., Kee, Y. K., Park, J. T., Chang, T. I., Kang, E. W., Yoo, T. H., Kang, S. W., \& Han, S. H. (2019). A diet rich in vegetables and fruit and incident CKD: a community-based prospective cohort study. American Journal of Kidney Diseases, 74(4), 491500 .

Karadeniz, F., Burdurlu, H. S., Koca, N., \& Soyer, Y. (2005). Antioxidant activity of selected fruits and vegetables grown in Turkey. Turkish Journal of Agriculture and Forestry, 29(4), 297-303. 
Kolniak-Ostek, J. (2016). Chemical composition and antioxidant capacity of different anatomical parts of pear (Pyrus communis L.). Food Chemistry, 203, 491-497.

Legua, P., Serrano, M., Melgarejo, P., Valero, D., Martínez, J. J., Martínez, R., \& Hernández, F. (2013). Quality parameters, biocompounds and antioxidant activity in fruits of nine quince (Cydonia oblonga Miller) accessions. Scientia Horticulturae, 154, 61-65.

Liu, H., Cao, J., \& Jiang, W. (2015). Evaluation and comparison of vitamin C, phenolic compounds, antioxidant properties and metal chelating activity of pulp and peel from selected peach cultivars. LWT-Food Science and Technology, 63(2), 10421048.

Liu, R. H. (2003). Health benefits of fruit and vegetables are from additive and synergistic combinations of phytochemicals. The American Journal of Clinical Nutrition, 78(3), 517-520.

Manzoor, M., Anwar, F., Mahmood, Z., Rashid, U., \& Ashraf, M. (2012). Variation in minerals, phenolics and antioxidant activity of peel and pulp of different varieties of peach (Prunus persica L.) fruit from Pakistan. Molecules, 17(6), 6491-6506.

Middleton E. J. R., \& Kandaswami, C. (1986). The ımpact of plant flavonoids on mammalian biology: Implications for ımmunity, Inflammation and cancer. In J.B. Harborne (Ed.), The Flavonoids (pp. 619-651). Chapman and Hall, London, England.

Öztürk, A., Demirsoy, L., Demirsoy, H., Asan, A., \& Gül, O. (2015). Phenolic compounds and chemical characteristics of pears (Pyrus communis L.). International Journal of Food Properties, 18(3), 536-546.

Papp, N., Szabó, T., Szabó, Z., Nyéki, J., \& Hegedűs, A. (2013). Antioxidant capacity and total polyphenolic content in quince (Cydonia oblonga Mill.) fruit. International Journal of Horticultural Science, 19(3-4), 33-35.

Rasheed, M., Hussain, I., Rafiq, S., Hayat, I., Qayyum, A., Ishaq, S., \& Awan, M. S. (2018). Chemical composition and antioxidant activity of quince fruit pulp collected from different locations. International Journal of Food Properties, 21(1), $2320-2327$.

Ricceri, F., Giraudo, M. T., Fasanelli, F., Milanese, D., Sciannameo, V., Fiorini, L., \& Sacerdote, C. (2017). Diet and endometrial cancer: a focus on the role of fruit and vegetable intake, Mediterranean diet and dietary inflammatory index in the endometrial cancer risk. BMC Cancer, 17(1), 757.

Rop, O., Balik, J., Řezníček, V., Juríková, T., Škardová, P., Salaš, P., Sochor, J., Mlcek, J., \& Kramářová, D. (2011). Chemical characteristics of fruits of some selected quince (Cydonia oblonga Mill.) cultivars. Czech Journal of Food Sciences, 29(1), 6573.

Shaida, B., Singh, N. B., \& Singh, K. (2020). In-vitro evaluation of anti-inflammatory and anti-microbial properties of ethanolic extract of Cydonia Oblonga seeds. Journal of Scientific \& Industrial Research, 79, 49-52.

Silva, B. M., Andrade, P. B., Ferreres, F., Domingues, A. L., Seabra, R. M., \& Ferreira, M. A. (2002). Phenolic profile of quince fruit (Cydonia oblonga Miller) (pulp and peel). Journal of Agricultural and Food Chemistry, 50(16), 4615-4618.

Silva, B. M., Andrade, P. B., Gonçalves, A. C., Seabra, R. M., Oliveira, M. B., \& Ferreira, M. A. (2004). Influence of jam processing upon the contents of phenolics, organic acids and free amino acids in quince fruit (Cydonia oblonga Miller). European Food Research and Technology, 218(4), 385-389.

Silva, B. M., Andrade, P. B., Martins, R. C., Valentão, P., Ferreres, F., Seabra, R. M., \& Ferreira, M. A. (2005). Quince (Cydonia oblonga Miller) fruit characterization using principal component analysis. Journal of Agricultural and Food Chemistry, 53(1), 111-122.

Silva, B. M., Seabra, R. M., Andrade, P. B., \& Papadopoulos, K. N. (2008). Quince (Cydonia oblonga Miller): an interesting dietary source of bioactive compounds. Editor: Konstantinos N. Papadopoulos. Food Chemistry Research Developments, $243-266$.

Stojanović, B. T., Mitić, S. S., Stojanović, G. S., Mitić, M. N., Kostić, D. A., Paunović, D. Đ., Arsic, B. B., \& Pavlović, A. N. (2017). Phenolic profiles and metal ions analyses of pulp and peel of fruits and seeds of quince (Cydonia oblonga Mill.). Food Chemistry, 232, 466-475.

Szychowski, P. J., Munera-Picazo, S., Szumny, A., Carbonell-Barrachina, Á. A., \& Hernández, F. (2014). Quality parameters, biocompounds, antioxidant activity and sensory attributes of Spanish quinces (Cydonia oblonga Miller). Scientia Horticulturae, 165, 163-170.

Thomas, M., Crépeau, M. J., Rumpunen, K., \& Thibault, J. F. (2000). Dietary fibre and cell-wall polysaccharides in the fruits of Japanese quince (Chaenomeles japonica). LWT-Food Science and Technology, 33(2), 124-131.

Tuna-Gunes, N., \& Dumanoglu, H. (2005). Some fruit attributes of quince (Cydonia oblonga) based on genotypes during the pre-harvest period. New Zealand Journal of Crop and Horticultural Science, 33(3), 211-217.

Valko, M., Leibfritz, D., Moncol, J., Cronin, M. T., Mazur, M., \& Telser, J. (2007). Free radicals and antioxidants in normal physiological functions and human disease. The International Journal of Biochemistry \& Cell Biology, 39(1), 44-84. 
Vieira, F. G. K., Borges, G. D. S. C., Copetti, C., Amboni, R. D. D. M. C., Denardi, F., \& Fett, R. (2009). Physico-chemical and antioxidant properties of six apple cultivars (Malus domestica Borkh) grown in southern Brazil. Scientia Horticulturae, 122(3), 421-425.

Wojdylo, A., Oszmianski, J., \& Bielicki, P. (2013). Polyphenolic composition, antioxidant activity, and polyphenol oxidase (PPO) activity of quince (Cydonia oblonga Miller) varieties. Journal of Agricultural and Food Chemistry, 61(11), $2762-2772$.

Wootton-Beard, P. C., \& Ryan, L. (2011). Improving public health?: The role of antioxidant-rich fruit and vegetable beverages. Food Research International, 44(10), 3135-3148.

Zhishen, J., Mengcheng, T., \& Jianming, W. (1999). The determination of flavonoid contents in mulberry and their scavenging effects on superoxide radicals. Food Chemistry, 64(4), 555-559. 